\title{
Failure to Launch, Failure to Achieve Criteria for Adulthood?
}

Journal of Adolescent Research $\mathrm{XX}(\mathrm{X}) \mathrm{I}-35$

(C) The Author(s) 2010

Reprints and permission: sagepub.com/journalsPermissions.nav DOI: $10.1177 / 0743558410371126$ http://jar.sagepub.com

@SAGE

\section{Evie Kins' and Wim Beyers'}

\begin{abstract}
In the West it is not until the mid-20s or 30 s people reach an adult status. Becoming an adult signifies being independent from others (especially from parents) and learning to stand alone as a self-sufficient person. This study investigates whether the attainment of such individual qualities are affected by emerging adults' living circumstances. Results indicate that though independent living is associated with an accelerated achievement of certain criteria for adulthood, continued coresidence with parents during emerging adulthood slows down the process by which an individual moves toward becoming a self-sufficient and independent adult. Because success in the achievement of an adult status also positively predicts emerging adults' wellbeing, delayed home-leaving during this stage of life is an issue that requires special attention.
\end{abstract}

\section{Keywords}

emerging adulthood, adult status, living situation, well-being

Economic and sociocultural changes in the West have resulted in the postponement of individuals to take on adult responsibilities. Arnett (2000) created the term emerging adulthood to refer to this period between adolescence and adulthood that is characterized by exploration, instability, possibilities, and self-focusing. In the past, the transition to an adult status was

'Ghent University, Ghent, Belgium

Corresponding Author:

Evie Kins, Department of Developmental, Personality, and Social Psychology, Henri Dunantlaan, 2, B-9000 Ghent, Belgium.

E-mail: evie.kins@ugent 
clearly marked by the arrival of certain role transitions an individual goes through, like, marriage and childbearing and becoming a parent. Although these role transitions are no longer predominant in today's definition of adulthood, it remains to be questioned whether delaying such transitions can affect the attainment of an adult status. As adulthood is nowadays defined as becoming independent, and learning to stand alone as a self-sufficient person (Arnett, 2004), special attention is warranted for the effect of delaying the transition toward residential independence on the achievement of an adult status. Therefore, this study investigated whether continued coresidence with parents during emerging adulthood can impede the achievement of an adult status. Furthermore, because research on the relationship between achieving an adult status and personal well-being is sparse, we examined whether emerging adults who are successful in achieving criteria for adulthood experience more subjective well-being compared with peers who fail to achieve those criteria.

\section{Delayed Entry Into Adulthood}

Whereas adulthood used to begin after a relatively brief adolescent period in the past, there is nowadays in Western postindustrial societies a general tendency to delay the transition to an adult status (Buhl \& Lanz, 2007; Fussell, Gauthier, \&, Evans, 2007; Settersten, Furstenberg, \& Rumbaut, 2005). The extended amount of education required in the West is often referred to as an explanation for young people's delay in the onset of taking on adult roles, like getting married or becoming parents (Gitelson \& McDermott, 2006). Historically, such role transitions have been considered the essential markers of adulthood. Marriage and childbearing, in particular, were allocated as the rites of passage to adulthood. These events clearly indicated that point in time when a boy became a man and a girl became a woman. However, nowadays only traditional cultures seem to retain this definition of adulthood (Arnett \& Galambos, 2003), whereas the current generation in Western postindustrial societies has renounced these role transitions as markers of adulthood, in favor of individualistic criteria (Arnett, 1998; Mayseless \& Scharf, 2003; Nelson \& Barry, 2005; Settersten et al., 2005). As a result, the entry into adulthood became more ambiguous, gradual, and less uniform (Settersten et al., 2005).

During the extended period toward adulthood, it is very likely that young people feel that though they are no longer adolescents, they are not fully independent adults as yet and that they are in a phase of transition only. Arnett (2000) introduced the concept emerging adulthood to refer to this 
distinct phase in life, which is situated between the late teens and early 20s. Emerging adulthood is distinguished from adolescence and (young) adulthood by its highly exploratory and unpredictable nature. During this life stage, young people get the most chances to experiment in the area of love, work, and worldviews without having to commit themselves to long-term adult roles and responsibilities.

Whereas the theory of emerging adulthood was developed in the United States, previous research (Buhl \& Lanz, 2007; Sirsch, Dreher, Mayr, \& Willinger, 2009) indicated that the young generation across Europe shares the five main features of this phase (identity exploration, instability, feeling in between, self-focusing, and possibilities; Arnett, 2000). Hence, although emerging adulthood is not considered a universal period, it can be generalized to other cultures where the onset of taking on adult roles and responsibilities is postponed. In Belgium, a small country situated in the Northwest of Europe where this study was conducted, the prolonged transition to adulthood is noticeable too. That is, postponement of traditional adult roles like marriage and becoming a parent is a fact in today's Belgian society. Between 1996 and 2005 the mean age of first marriage for women increased from 26 to 28.3 years, and for men from 28.2 to 30.8 years, whereas the mean age of women having their first child increased to 28 years in 1999 (National Institute for Statistics [NIS], 2008). As said earlier, the high level of education partially might explain this delay. In Belgium, $42 \%$ of the 18 - to 25 -year-olds are still students, of whom the majority are enrolled in higher education (Vettenburg, Elchardus, \& Walgrave, 2007).

At the end of emerging adulthood, the mid-to-late 20s, most people feel that they have reached adulthood. However, as traditional markers of adulthood are renounced, what does becoming an adult in today's Western society actually mean? Arnett $(1998,2001,2003,2004)$ extensively studied this question in various parts of the United States, and across different ethnic groups and social classes. On the basis of sociological, anthropological, and psychological perspectives on adulthood, he created a questionnaire to examine how adulthood is currently conceptualized. Guided by theoretical rather than statistical considerations, the items of this questionnaire (expressing possible criteria for adulthood) were organized into subscales, including independence, interdependence, role transitions, norm compliance, family capacities, biological, and chronological transitions. Respondents indicate whether they believe each of these criteria must be achieved before a person can be considered an adult. Three criteria that consistently emerged as most important markers of adulthood for (young) people today are as follows: accepting responsibility for one's self, making independent decisions, and 
being financially independent (Arnett, 1998, 2001, 2003). As all these items refer to independence, it can be concluded that achieving an adult status in today's Western societies signifies becoming independent from others (especially from parents) and learning to stand alone as a self-sufficient person (Arnett, 2004).

Although role transitions are no longer predominant in the conceptualization of adulthood, they possibly continue to play an important role in the achievement of an adult status. In line with this assumption, a sociological study indicated that young people who have experienced role transitions, like establishing an independent household, getting married or cohabiting, or becoming a parent, are actually more likely to report feeling like an adult (Settersten et al., 2005). In a recent Belgian study (Luyckx, Schwartz, Goossens, \& Pollock, 2008), which focused exclusively on the impact of entrance into work life on achieving a sense of adulthood, it was also confirmed that emerging adults who made this specific role transition view themselves more as adults. Furthermore, when emerging adults grow to more self-understanding, they seem to attribute this growth largely to eventful experiences such as the transition to university or living independently (Gottlieb, Still, \& Newby-Clark, 2007).

An important question that remains is whether the achievement of the individualistic character qualities that primarily define adulthood in today's context is in fact accelerated when emerging adults have experienced certain role transitions. In this study, we examined the impact of one specific type of role transition, that is, leaving the parental home for the transition to residential independence.

\section{Leaving the Parental Home}

Several sociological studies indicated that the average age at which young people leave the parental home and gain full residential independence has increased profoundly in the West since the 1980s (Galland, 1997; Goldscheider, 1997; Goldscheider \& Goldscheider, 1999). As a result, it is, in today's context, no longer exceptional to coreside with parents in your 20 s or even in your 30s. In Flanders, the Dutch-speaking part of Belgium, a recent demographic report indicated that the trend of delayed home leaving even continued to increase between 1990 and 2007. In particular, the number of women coresiding with parents seems to have increased in these past decades. Nevertheless, (emerging) adult men still outnumber women when it comes to living in the parental home. Whereas $55 \%$ of the 20 - to 24 -year-old women coresided with parents in 1990 , this increased to $64 \%$ in 2007 . For men in this 
age group this percentage rose more steadily from $74 \%$ in 1990 to $78 \%$ in 2007. The amount of 25- to 29-year-old emerging adults living with the parents increased as well, between 1990 and 2007, from 14\% to $29 \%$ for women and from $28 \%$ to $35 \%$ for men (Lodewijckx, 2008). In Southern European countries, this trend of delayed home leaving is even more pronounced than in Northern Europe or the United States (Cherlin, Scabini, \& Rossi, 1997). For instance, data from a large European panel study indicated the latest home-leaving patterns are found in Mediterranean countries, and particularly in Italy where it is not until age 27 that half of all Italian women are found to be living away from home, and for nearly half of Italian men, it does not happen until almost age 30 (Iacovou, 2001).

Possibly, this overall trend of delayed home leaving is detrimental for the achievement of an adult status. That is, emerging adults who no longer live in the parental household could be more capable of achieving individualistic character qualities that currently conceptualize adulthood than do young people who continue to coreside with parents. According to Goldscheider and Goldscheider (1999), residential independence is indeed a critical step in the transition to adulthood. A similar prediction can be made on the basis of separation-individuation theory (SIT; Blos, 1967, 1979). The renegotiation of the parent-child relationship when a child moves to adolescence is a key component of the SIT. As a child grows up and gains more individuality, the hierarchical parent-child relationship should be transformed into a more symmetrical relationship between two caring and respecting adults (Grotevant \& Cooper, 1986). Tanner (2006) situated the onset of this process at the beginning of emerging adulthood and refers to it as "recentering." Recentering highlights the relational restructuring between the emerging adult and his or her family of origin that takes place as a result of the shift in orientation from parent regulation to self-regulation. During this process of recentering, the parent-child relationship is challenged to transform itself to an adult relationship in which adult children are afforded the freedom to make choices and decisions on the basis of their own beliefs and values while maintaining an ongoing relatedness.

Evidence has shown that leaving the parental home can serve as a catalyst for the transformation of the parent-child relationship toward mutuality. Aquilino (1997), for instance, found that when a child has left the parental home, parents are more competent to reevaluate the relationship with their child because they are more capable to acknowledge that their child has entered a new stage in life. Although the results of this study indicated that most major life transitions generate an opportunity to change the former infantile parent-child relationship into a more adult-like relationship, home 
leaving marks a transitional phase that has the most power to reorganize earlier styles of relating. Similarly, Flanagan, Schulenberg, and Fuligni (1993) found that the redefinition of the relationship with parents was more problematic when parents and children were still living under the same roof. Young people living with their parents felt that their parents continued to treat them as children; this explains why they experience less independence and mutuality in the relationship with their parents.

However, it is not just parents who seem to find it difficult to relinquish their care-taking role when their adult child is living in the parental household, but young people themselves who are coresiding with their parents often continue to behave in immature and dependent ways, mostly out of habit and not willing to take full responsibility for themselves. This prevents the fledging adult from developing new relationships and from taking greater responsibility for his or her life (Clemens \& Axelson, 1985). Hence, it seems likely that emerging adults who live with parents not only fail to establish a symmetrical parent-child relationship, but what is more, they seem to be less successful in achieving an adult status in general (Elm \& Schwartz, 2006; White, 2002).

\section{Well-Being}

Continued coresidence with parents during emerging adulthood thus possibly hampers the achievement of an adult status and of a sense of independence in particular. However, is failing to achieve an adult status inevitably detrimental to emerging adults' overall well-being? Given that current Western societies are very strongly oriented toward youthfulness (Fry, 1996), one could intuitively reason that becoming an adult will have a negative connotation. Hence, it might be the case that individuals who relinquish adult responsibilities and avoid making lifelong commitments will experience the highest level of personal well-being. At the same time, this dissolute type of lifestyle can also generate confusion and disequilibrium, as it provides little certainty and purpose in life (Erikson, 1968).

Literature on the relationship between the transition to adulthood and subjective well-being is sparse, and to date research has only yielded indirect evidence for the latter proposition. That is, during the transition to adulthood, emerging adults in general demonstrate improved psychological well-being as a part of their growing psychosocial maturity (Galambos, Barker, \& Krahn, 2006; Galambos \& Krahn, 2008). In particular, emerging adults demonstrated significant decreases in depressive symptoms and anger and significant increases in self-esteem over time. Because increased 
decision-making power and independence are rated as the most important criteria for reaching adulthood (Arnett, 2003), these scholars presume that mainly transition-linked increases in these features accompany increases in psychological well-being. Further research that verifies this assumption is lacking, however.

Another longitudinal study that specifically focused on salient and quite visible developmental tasks during the transition to adulthood (i.e., education, work, financial autonomy, romantic involvement, peer involvement, substance abuse avoidance, and citizenship) found that individuals who were more successful in achieving these tasks maintained or gained a salutary trajectory of well-being across all three waves of the study (Schulenberg, Bryant, \& O’Malley, 2004). Particularly success in work, romantic involvement, peer involvement, and citizenship appeared crucial to maintain high well-being.

\section{The Present Study}

The present study has three primary research goals. First, we studied whether people in their early-to-mid -20s, irrespective of their living arrangements, are actually involved in making the transition to become an adult, as presumed by Arnett (2000). Therefore, we explored the changes emerging adults make in the achievement of criteria for adulthood during 1 year. On the basis of the theory of emerging adulthood, we hypothesized that the majority of emerging adults in our sample will have proceeded in the transition toward adulthood, and thus, that participants will increasingly endorse that they achieved the criteria for adulthood. Second, we investigated the impact of delayed home leaving on the achievement of an adult status. It was hypothesized that emerging adults living with their parents will feel less adult, and thus, will have achieved less criteria of adulthood, compared with peers who have already taken steps toward independent living. Next, we also studied whether progress in achievement of adult criteria after 1 year, is moderated by the change that is made in one's living situation during that year. It is hypothesized that emerging adults who move toward a more independent type of living situation will make more progress compared with peers who continue to live with their parents or who came back to live in the parental home again after a period of independent living. The last main goal of this study was to investigate the relationship between the transition toward an adult status and subjective well-being. On the basis of the findings of the few studies on this topic, it was hypothesized that emerging adults who are less successful in achieving criteria for adulthood, and perhaps in particular criteria that refer to independence, will experience less subjective well-being. 


\section{Method}

\section{Participants and Procedure}

Our sample comprised 224 emerging adults living in Flanders, the Dutchspeaking part of Belgium. Because we are primarily interested in uncovering the relationship between emerging adults' residential status and the achievement of adult criteria, we deliberately chose to obtain a sample with a virtually equal number of emerging adults who coreside with their parents and emerging adults who no longer permanently live in the parental home. For the purpose of data collection, living away from the parents was arbitrarily defined as staying at the parental home a maximum of once a month, on average. In what follows, the categorization of emerging adults' living situation will be refined on the basis of statistical argumentation. This procedure resulted in a sample with approximately half of the participants coresiding with their parents $(58 \%)$ and half living independently (42\%). Furthermore, we also aimed to balance our sample with respect to gender and level of education. Hence, practically an equal number of men (52\%) and women (48\%) participated in this study sample, as well as a comparable number of highly educated (58\%) and low-educated emerging adults (42\%). Especially, this last group, which consists of college dropouts and of persons who dropped out during or after having completed high school, is often neglected in research focusing on emerging adulthood. To obtain this balanced sample, a stratified sampling technique was used with living situation (with parents vs. independent), gender (male vs. female), and education (low vs. high) level as the stratification variables. As these three variables were used simultaneously to stratify the sample, eight combinations or strata were obtained from which we attempted to retrieve an equal number of subjects. As a result, almost as much highly educated men and women as lower educated men and women were included in both the coresiding with parents subgroup and the independently living subgroup.

All participants were born in 1983 or 1984 and were 22 to 23 years old ( $M=22$ years and 10 months, $S D=8$ months) at the onset of the study. This age group was chosen because in Belgium an exit from the parental home before the age of 22 occurs rarely (5\%). Nevertheless, at the age of 25 more than half of the Belgian emerging adults no longer live with their parents (Vettenburg et al., 2007). Hence, between the ages of 22 and 25 changes with respect to the living situation start occurring for a lot of young people, which makes this age group particularly interesting for this study. Participants were contacted by the first author or by psychology students. All emerging adults received a letter explaining the purpose of the study, an informed consent 
form, and a questionnaire. Participation in this study was completely voluntary and could be refused at any point in time. Questionnaires were administered at the participant's home and returned to the student or by mail. The majority of the emerging adults who agreed to participate in this study came from intact families (75\%); that is, both parents were living together in the same household.

One year later, all 224 emerging adults were contacted again by psychology students or by mail to fill out a new questionnaire. From the initial sample, $82 \%$ of the participants $(N=183)$ were willing to participate in the next wave of data collection. Participants of both data waves (Time 1 and Time 2) were compared with those who dropped out after the first point of measurement (Time 1) in terms of gender, level of education, type of living situation, and family structure. Emerging adults who participated in both data waves were more likely to be highly educated than those who dropped out, $\chi^{2}(1, N=224)=7.83, p<.01$. With respect to the other background variables, there were no significant differences between the two groups. Further attrition analyses revealed that dropouts and those who continued with participation did not differ significantly with respect to the study variables measured at Time 1: the various criteria for adulthood: $F(32,155)=$ $1.09, n s$, and subjective well-being: $F(3,220)=0.67, n s$. Moreover, Little's (1988) test indicated that data were missing completely at random (MCAR), $\chi^{2}(2,283, N=224)=2410.86, n s$. Therefore, the expectation-maximization (EM) algorithm was used for data imputation, a robust method to obtain maximum likelihood estimates (Schafer, 1997). As a consequence, the sample used for all analyses was $N=224$.

\section{Measures}

All questionnaires were administered in Dutch, participants' mother tongue. Questionnaires not available in Dutch were translated according to the guidelines of the International Test Commission (Hambleton, 1994). All questionnaires are self-report measures and were administered both at Time 1 and Time 2.

Living situation. To obtain a clear picture about the participants' living arrangements both at Time 1 and Time 2, emerging adults were asked to respond to some detailed questions about their residential status. First, they were asked to indicate where they currently lived by choosing one of the following categories: with both of my parents, with one of my parents, alone, with my partner, in a student's apartment, or other. Next, emerging adults not living with parents were asked to specify how far their present residence was 
located from the parental home: within walking distance, in a neighboring town, between 20 and $50 \mathrm{~km}$, between 50 and $100 \mathrm{~km}$, and more than $100 \mathrm{~km}$. Emerging adults living away from their parents were also asked to report how often they stay over at their parents' home. Answers ranged from once a week, once in 2 weeks, once a month, occasionally or never. Finally, one specific criterion of Arnett's (2003) questionnaire to measure the conceptualization of adulthood was also considered, namely, "No longer living in the household of your parent(s)." Participants had to indicate whether they had achieved this criterion on a 3-point scale.

Adulthood. To measure the achievement of an adult status, we used an adapted version of Arnett's questionnaire containing criteria for adulthood. That is, instead of asking emerging adults whether they think each of the criteria must be achieved before a person can be considered an adult, we sought to know whether participants in our sample had achieved each of these criteria themselves. Response options were: no, in some respects yes and in some respects no, and yes. Although Arnett's questionnaire also contains the item, "Do you think that you have reached adulthood?," we believe that specifying the achievement of each criterion for adulthood allows for a detailed picture of the achievement of adulthood to emerge. Some criteria appeared to be irrelevant for the participants in our sample (e.g., "Reached the age of 18 " and "Reached the age of 21 ") and were, therefore, excluded.

The various criteria of adulthood, drawn from specific literatures, are organized into subscales on the basis of theoretical considerations rather than on statistical ground (Arnett, 2001). Subscales included the following: independence, interdependence, role transitions, norm compliance, family capacities, biological, and chronological transitions (Arnett, 2001, 2003). Internal consistencies of these subscales have shown to be moderate, with consistently low alpha levels reported for the independence (.42 to .53) and interdependence (.64 to .67) subscale (Arnett, 2003; Nelson \& Barry, 2005; Sirsch et al., 2009). Reliability analyses pointed out that alpha levels of these subscales were even worse in our sample, both at Time 1 and Time 2: alpha values for independence subscale were. 36 to .44 , and .11 to .22 for the interdependence subscale. Internal consistencies of the other subscales were moderate, ranging from .56 to .67. Furthermore, attempts to replicate Arnett's conceptually derived domains using factor analyses failed both at Time 1 and Time 2, with poor overall fit and very low factor loadings, particularly for the independence and interdependence factors. Other studies also failed to replicate these factors (Badger, Nelson, \& Barry, 2006; Mayseless \& Scharf, 2003). Hence, it can be concluded that although Arnett's conceptual model shows high face validity (e.g., Barker \& Galambos, 2005), statistical evidence 
for this model is lacking. Therefore, it was decided to continue our analyses on the item level instead of calculating subscale scores. Consequently, the analyses will have a more descriptive character. Nevertheless, they are considered to be interesting, as the items of this questionnaire refer to various ways of thinking about adulthood.

Subjective well-being. Three scales were used to assess subjective wellbeing, namely, the Satisfaction With Life Scale (SWLS; Diener, Emmons, Larsen, \& Griffin, 1985), the Subjective Vitality Scale (SVS; Ryan \& Frederick, 1997), and the Center for Epidemiologic Studies-Depression Scale (CES-D; Radloff, 1977). The SWLS is a commonly used questionnaire that consists of five items, each tapping how (un)satisfying people cognitively judge their lives. All items were scored on a 7-point Likert-type scale, ranging from 1 (strongly disagree) to 7 (strongly agree). A sample item reads, "In most ways my life is close to ideal." Reliability and validity of this scale has been repeatedly demonstrated (e.g., Diener et al., 1985; Pavot, Diener, Colvin, \& Sandvik, 1991). In our sample of emerging adults Cronbach's alpha was .84 at Time 1 and .86 at Time 2. Second, the SVS measures well-being from a rather affective perspective. A sample item reads, "Currently, I feel so alive I just want to burst." All 7 items were scored on a 5-point Likert-type scale, ranging from 1 (strongly disagree) to 5 (strongly agree). This questionnaire was previously translated in Dutch by Niemiec et al. Both the original English and Dutch version of this short questionnaire have shown good reliability and validity (Niemiec et al., 2006; Ryan \& Frederick, 1997). Cronbach's alpha in our study was .81 both at Time 1 and Time 2. Third, distress and depressive symptoms were measured with the 12-item version of the CES-D. Items reflect somatic, cognitive, and emotional symptoms of depression. Respondents indicated how often they had suffered from these symptoms during the past week on a 4-point Likert-type scale, ranging from 0 (never or seldom) to 3 (mostly or always). Hanewald (1987) translated this scale to Dutch. Previous research demonstrated concurrent validity and reliability of the Dutch version of the CES-D (Bouma, Ranchor, Sanderman, \& van Sonderen, 1995). In our sample Cronbach's alpha was .87 at Time 1 and .86 at Time 2 .

All three scales were considered as measures of the same underlying construct, that is, subjective well-being. Factor analyses supported this idea, with all 3 scales loading substantially on one factor explaining $66.96 \%$ and $69.79 \%$ of the variance at Time 1 and Time 2, respectively. Consequently, instead of working with separate scores for SWLS, SVS, and CES-D, we computed a factor score that can be regarded as a composite score of the three scales reflecting overall subjective well-being. 


\section{Results}

\section{Types of Living Situations}

During data collection, living arrangements of emerging adults were categorized as coresiding with parents or living independently, depending on the monthly rate of their staying over in the parental home. However, today young people's residential status is no longer restricted to either living with parents or starting an independent household. Living separately from the parents but returning to the parental home frequently, without having to take all the responsibilities associated with living completely independent, has become a popular alternative for many emerging adults (de Jong Gierveld, Liefbroer, \& Dourleijn, 2001). These more intermediate forms of living situations have often been denoted as semiautonomous (Goldscheider \& DaVanzo, 1986). Hence, in order to take into account the heterogeneity of emerging adults' residential status we performed a latent class analysis (LCA with LEM software; Vermunt, 1997) using the questions that tap into different aspects of the living situation as indicators. On the basis of the results of LCA, participants were categorized into one of three living situations both at Time 1 and Time 2: coresiding with parents, semiindependent, or independent. For more details on this type of analysis and clear evidence for a solution with three underlying categories of living arrangements at Time 1, see Kins, Beyers, Soenens, and Vansteenkiste (2009). At Time 2 the same 3-category solution was replicated. The selection of the number of classes was made on the basis of a number of robust criteria for class enumeration: Bayesian information criterion (BIC), bootstrapped likelihood ratio test (BLRT), and average posterior probabilities (Nylund, Asparouhov, \& Muthén, 2007). First, comparing BIC values across the different models tested shows that a model with three latent classes yields a better fit $\left(L^{2}=132.72, d f=596, p=1.00, \mathrm{BIC}=-3,066.51\right)$ than a model with two (BIC $=-3,028.75)$ or four latent classes $(\mathrm{BIC}=-3,000.33)$. Next, the highly significant $(p<.001)$ BLRT's comparing a model with two and three latent classes gave further evidence for our 3-class solution. Finally, average posterior probabilities added support to the model with three classes (.95) over a 4-class model (.92).

As was the case at Time 1, probabilities at Time 2 also reflected that the first latent class included participants living permanently with one or both of their parents $(p=.98)$ and who believe that they have not yet achieved independent living $(p=.70)$. This group was labeled coresiding with parents. The second class comprised emerging adults with various residential statuses (living in a student's apartment, $p=.29$; alone, $p=.23$; with a partner, $p=.20$; or other, like sharing a house with friends, $p=.14$ ). Nevertheless, this class 
clearly represented young people who live between 20 to $100 \mathrm{~km}$ away from the parental home $(p=.72)$ but return every weekend to stay over with their parents $(p=.40)$ and who score in between with respect to the question tapping the achievement of an independent living situation $(p=.44)$. Therefore, this category was labeled semiindependent. The final class consisted of emerging adults who live either alone $(p=.18)$ or with a partner $(p=.80)$, mainly within walking distance from the parental home or in a neighboring town $(p=.73)$. These participants reported that they never or rarely stay over with their parents $(p=.93)$, and they consider themselves to have achieved the status of living independently $(p=.99)$. They were labeled independent.

On the basis of these results, conditional probabilities were used to assign all emerging adults in our study to one of the three subtypes of residence. At Time 2, 34\% of the emerging adults were categorized as coresiding with parents, $30 \%$ as semiindependent, and $36 \%$ as independent (at Time 1, these percentages were, respectively, $36 \%, 24 \%$, and $40 \%$; see Kins et al., 2009). Even though only $20 \%$ of the participants reported to be students at Time 2, they comprised almost half (i.e., 47\%) of the emerging adults in the semiindependent-living condition, contrary to $19 \%$ of those coresiding with parents and $4 \%$ of those living independently (at Time $1,35 \%$ of the participating emerging adults were still enrolled in education, with $76 \%$ of the semiindependent being students versus $25 \%$ and $19 \%$ in the coresiding and independent group, respectively). The living situation of emerging adults seemed to remain fairly stable in our 1-year follow-up study. That is, $66 \%$ remained in the same type of living arrangement as the year before (25\% stable coresiding with parents; $13 \%$ stable semiindependent, and $28 \%$ stable independent), whereas $15 \%$ moved toward a more independent type of living (i.e., progression from coresiding with parents/semiindependent to independent living or from coresiding with parents to semiindependent) and 19\% regressed toward a less independent type of living situation.

\section{Descriptive Statistics}

First, the rate of achievement of the different criteria for adulthood was explored in our total sample of emerging adults both at Time 1 and Time 2 . Taking a look at the various items in detail (Table 1), it seems that most criteria comprising norm compliance, and especially criteria reflecting biological/chronological transitions, were at Time 1 and Time 2 obtained by the majority of our participants. Due to the lack of variability in these criteria, they were dropped from all further analyses. Criteria that reflect independence, interdependence, role transitions, and family capacities show a more 
Table I. Percentages of Emerging Adults Not Having Achieved (0)—Having Achieved in Some Respects, but Not in Others (I) - and Having Achieved (2) Each of Arnett's Criteria for Adulthood

\begin{tabular}{|c|c|c|c|c|c|c|}
\hline \multirow[b]{2}{*}{ Criteria for Adulthood } & \multicolumn{3}{|c|}{ Wave I } & \multicolumn{3}{|c|}{ Wave 2} \\
\hline & 0 & I & 2 & 0 & I & 2 \\
\hline \multicolumn{7}{|l|}{ Independence } \\
\hline $\begin{array}{l}\text { Establish relationship with parents as an } \\
\text { equal adult }\end{array}$ & 13 & 46 & 38 & 9 & 41 & 50 \\
\hline Being financially independent from parents & 27 & 25 & 47 & 18 & 16 & 66 \\
\hline No longer living in the parents' household & 37 & 16 & 45.5 & 31 & 17 & 52 \\
\hline Not deeply tied to parents emotionally & 26 & 51 & 20 & 7 & 47 & 46 \\
\hline $\begin{array}{l}\text { Accept responsibility for the consequences } \\
\text { of his or her actions }\end{array}$ & 2 & 17 & 79.5 & 0 & 9 & 91 \\
\hline $\begin{array}{l}\text { Decide on personal belief/values } \\
\text { independently of parents or other } \\
\text { influences }\end{array}$ & 3 & 28 & 68 & 1 & 19 & 80 \\
\hline \multicolumn{7}{|l|}{ Interdependence } \\
\hline Committed to a long-term love relationship & 25 & 19 & 55 & 18 & 15 & 67 \\
\hline Make lifelong commitments to others & 10 & 37 & 51 & 4 & 27 & 69 \\
\hline $\begin{array}{l}\text { Learn to always have good control of his or } \\
\text { her emotions }\end{array}$ & 17 & 57 & 25 & 5 & 56 & 39 \\
\hline $\begin{array}{l}\text { Become less self-oriented, develop greater } \\
\text { consideration for others }\end{array}$ & 3 & 60 & 35 & 0 & 50 & 50 \\
\hline \multicolumn{7}{|l|}{ Role transitions } \\
\hline Finished with education & 32 & 16 & 50 & 16.5 & 16.5 & 67 \\
\hline Married & 91 & 3 & 4 & 87 & 5 & 8 \\
\hline Have at least one child & 92 & 2 & 5 & 90 & 2 & 8 \\
\hline Employed full-time & 38 & II & 49 & 21 & 4 & 75 \\
\hline Settle into a long-term career & 47 & 28 & 24 & 20 & 34 & 46 \\
\hline Purchased a house & 79 & 7 & 12 & 6 & II & 20 \\
\hline \multicolumn{7}{|l|}{ Norm compliance } \\
\hline Avoid becoming drunk & 27 & 38 & 33 & 14 & 36 & 50 \\
\hline Avoid using illegal drugs & 5 & 15 & 78 & 5 & 9 & 86 \\
\hline Avoid drunk driving & 6 & 18 & 75 & 9 & 18 & 73 \\
\hline $\begin{array}{l}\text { Avoid committing petty crimes like } \\
\text { shoplifting and vandalism }\end{array}$ & 1 & 3 & 93 & 3 & 2 & 95 \\
\hline Have no more than one sexual partner & 24 & 10 & 65 & 12 & 6 & 82 \\
\hline Drive safely and close to speed limit & 18 & 39 & 43 & 12 & 28 & 60 \\
\hline Avoid use of profanity/vulgar language & 15 & 43 & 41 & 8 & 46 & 46 \\
\hline $\begin{array}{l}\text { Use contraception if sexually active and not } \\
\text { trying to conceive a child }\end{array}$ & 7 & 10 & 82 & 4 & II & 84 \\
\hline
\end{tabular}


Table I. (continued)

\begin{tabular}{|c|c|c|c|c|c|c|}
\hline \multirow[b]{2}{*}{ Criteria for Adulthood } & \multicolumn{3}{|c|}{ Wave I } & \multicolumn{3}{|c|}{ Wave 2} \\
\hline & 0 & I & 2 & 0 & I & 2 \\
\hline \multicolumn{7}{|l|}{ Biological/chronological transitions } \\
\hline Grow to full height & 5 & 3 & 91 & 3 & I & 96 \\
\hline Biologically capable of having children & 13 & II & 7I & 6 & 6 & 88 \\
\hline Have had sexual intercourse & 6 & 3 & 88 & 5 & 2 & 93 \\
\hline Obtained driver's license & 17 & 2 & 79 & 13 & 3 & 84 \\
\hline \multicolumn{7}{|l|}{ Family capacities } \\
\hline Capable of supporting a family financially & 39 & 27 & 32 & 26 & 22 & 52 \\
\hline Capable of caring for children & 29 & 39 & 31 & 24 & 41 & 35 \\
\hline Capable of running a household & 8 & 39 & 52 & 5 & 27 & 68 \\
\hline Capable of keeping a family physically safe & 29.5 & 41 & 27 & 13 & 32 & 55 \\
\hline
\end{tabular}

mixed pattern, with some criteria being highly endorsed by most participants, some by approximately half of the emerging adults and some by practically nobody. For instance, although most participants accept responsibility for their actions and make independent decisions, other criteria reflecting independence are yet to be obtained by many emerging adults in our sample. This is particularly true for the achievement of criteria that reflect the relinquishing of the earlier hierarchical parent-child relationship (i.e., establish adult relationship with parents and not deeply tied to parents emotionally) and the attainment of financial independence from parents. The percentages in Table 1 also show that emerging adults in our sample are highly involved in making the transition from school to work, as there is a substantial number of them who report being finished with education and employed full-time. Other role transitions like marriage and having children were, however, rarely achieved. As criteria that are grasped as interdependence and family capacities were only endorsed by half of the participants or less; these too are characteristics that still have to be attained by many emerging adults in our sample.

As a result of our balanced sampling technique, approximately half of the participants reported having achieved residential independence at Time 1 and Time 2. Because we also used this item as in indicator in the LCA to identify the types of living arrangements of the emerging adults in our sample, it was decided to remove this criterion from all further analyses where the achievement of the various criteria for adulthood is considered conditional on one's type of living arrangement. 


\section{Preliminary Analyses}

We first examined effects of background variables. A MANCOVA was conducted with the criteria for adulthood at Time 1 and Time 2 as dependent variables and emerging adults' gender, education level, age, family structure (intact or not), and relationship status (having a partner or not) at Time 1 as independent variables. Significant multivariate effects showed up for gender, $F(54,164)=2.84, p<.001, \eta^{2}=.48$; education level, $F(54,164)=3.73, p<$ $.001, \eta^{2}=.55$; family structure, $F(54,164)=1.74, p<.01, \eta^{2}=.36$; and relationship status, $F(54,164)=6.09, p<.001, \eta^{2}=.67$.

First, women tend to have achieved more criteria reflecting norm compliance than men do. Men, on the other hand, seem to be more successful in the area of work/career. Furthermore, significantly more men seem to be able to make independent decisions, to have good control of their emotions, and to protect a family physically. Second, highly educated emerging adults reported being more norm compliant than peers with less years of education. Emerging adults who received no education beyond high school, nevertheless seem to have attained a more solid financial base. They also have experienced more role transitions and evaluate their family capacities higher than their highly educated peers. Third, emerging adults coming from intact families judged their achievement on various criteria of adulthood higher than emerging adults from nonintact families did. Particularly, family capacities were endorsed more often when emerging adults originated from families where both parents live together. Moreover, emerging adults from intact families also scored higher with regard to the achievement of some norm compliance criteria, and also with respect to establishing a relationship with parents as an equal adult, accepting responsibility for the consequences of their actions and becoming less self-oriented. Fourth, participants involved in a romantic relationship scored particularly higher regarding the achievement of role transitions and family capacities. Furthermore, these emerging adults report having a more equal relationship with their parents and being more financially independent from parents. Probably as a logical consequence of their relationship status, they also endorsed commitment to a long-term love relationship, making lifelong commitments to others, and having no more than one sexual partner more often than their single peers. In sum, because these four background variables have a substantial impact on the achievement of the various criteria of adulthood, we controlled for the effect of gender, level of education, family structure, and relationship status in all subsequent analyses.

\section{Achievement of Adult Criteria and Living Situation}

Time 1. We conducted a set of MANCOVAs to investigate whether the achievement of adult criteria at Time 1 differs depending on the emerging 
adults' living situation at that time. A separate analysis was performed for each set of items Arnett organized into the same subscale. Results show significant multivariate effects of living situation on criteria representing independence, $F(8,426)=2.45, p<.05, \eta^{2}=.09$; interdependence, $F(10$, $424)=4.29, p<.001, \eta^{2}=.04$; role transitions $F(12,422)=4.01, p<.001$, $\eta^{2}=.10 ;$ and family capacities, $F(8,426)=8.79, p<.001, \eta^{2}=.14$.

Results of the univariate analyses, presented in Table 2, showed that, among the various criteria referring to independence, living situation only had an effect on being financially independent from parents. Post hoc Tukey tests indicated that emerging adults living independently rely the least on their parents for financial resources, followed by emerging adults who coreside with their parents. Emerging adults living semiindependent display the lowest financial independence from parents. Regarding the achievement of interdependence, significant univariate effects of type of living situation were found on criteria reflecting commitment to others or to long-term love relationships, with the independent group scoring higher than both the semiindependent and those coresiding with parents.

Furthermore, univariate effects of living situation on all role transitions in Arnett's questionnaire were found. Post hoc testing revealed that the independent living participants reported being married, having a child, a longterm career, and a house more frequently than did the semiindependent and the emerging adults coresiding with parents. With respect to finishing education and being employed full-time, both the independent living and those living with their parents scored higher than the semiindependent. A small univariate effect emerged on one of the norm compliance criteria (i.e., using contraception), but it was not confirmed by the multivariate test including all norm-compliance criteria.

Finally, type of living situation during emerging adulthood also affected the achievement of family capacities. Two significant univariate effects were found. That is, independently living participants endorsed being more capable of supporting a family financially than did those coresiding with parents, who, in turn, scored higher than those living semiindependently. Participants belonging to the independent group also outscored all others in the capability of running a household.

Change from Time I to Time 2. We also wanted to investigate whether the degree of change in achievement of adult criteria over a 1-year period depends on change or stability in the type of living situation ( $\Delta=$ living situation). That is, emerging adults either moved toward a more (progression group) or a less (regression group) independent type of living, or they continued to live with parents (stable with parents), semiindependent (stable semiindependent), or independent (stable independent). For this purpose, 


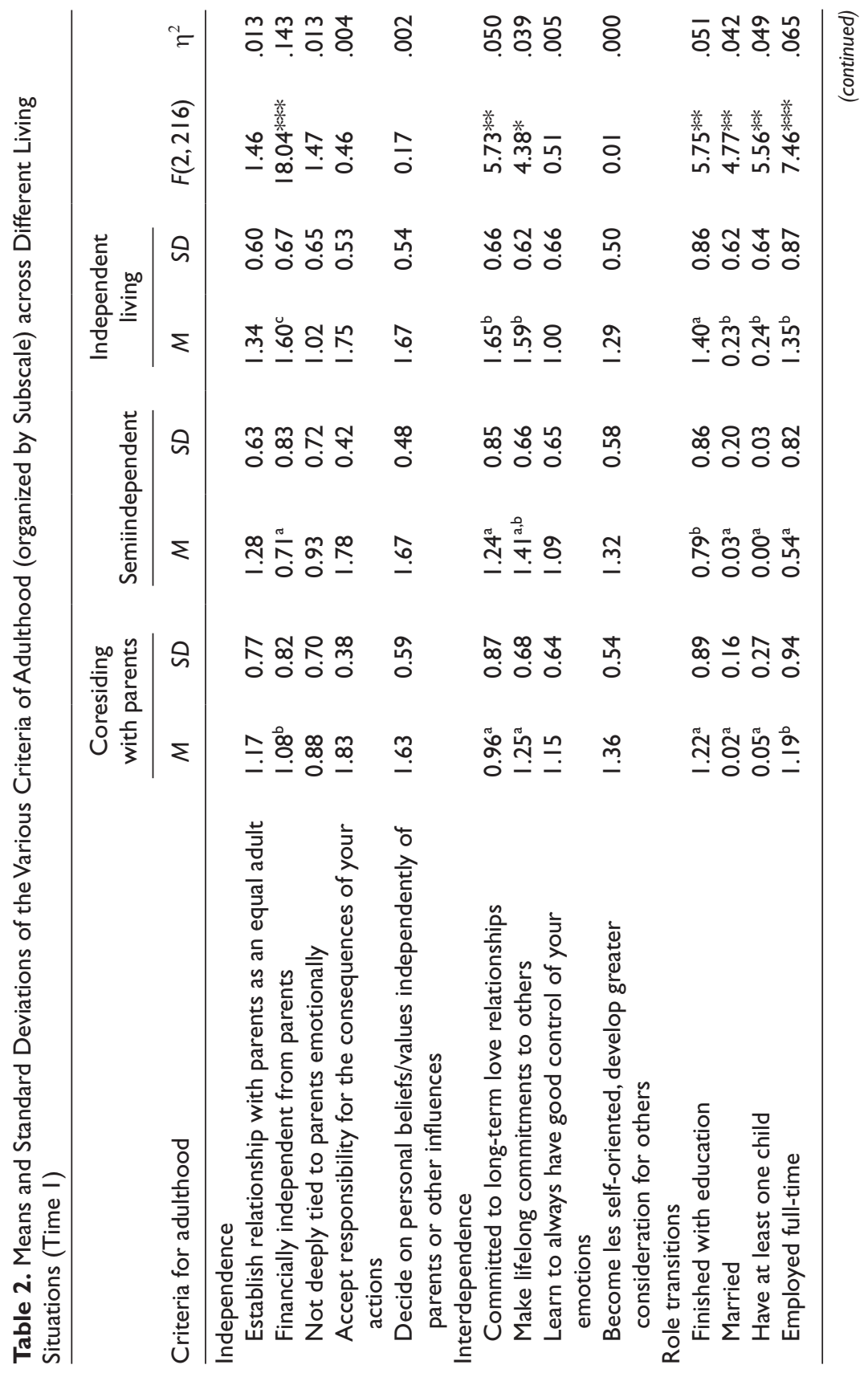




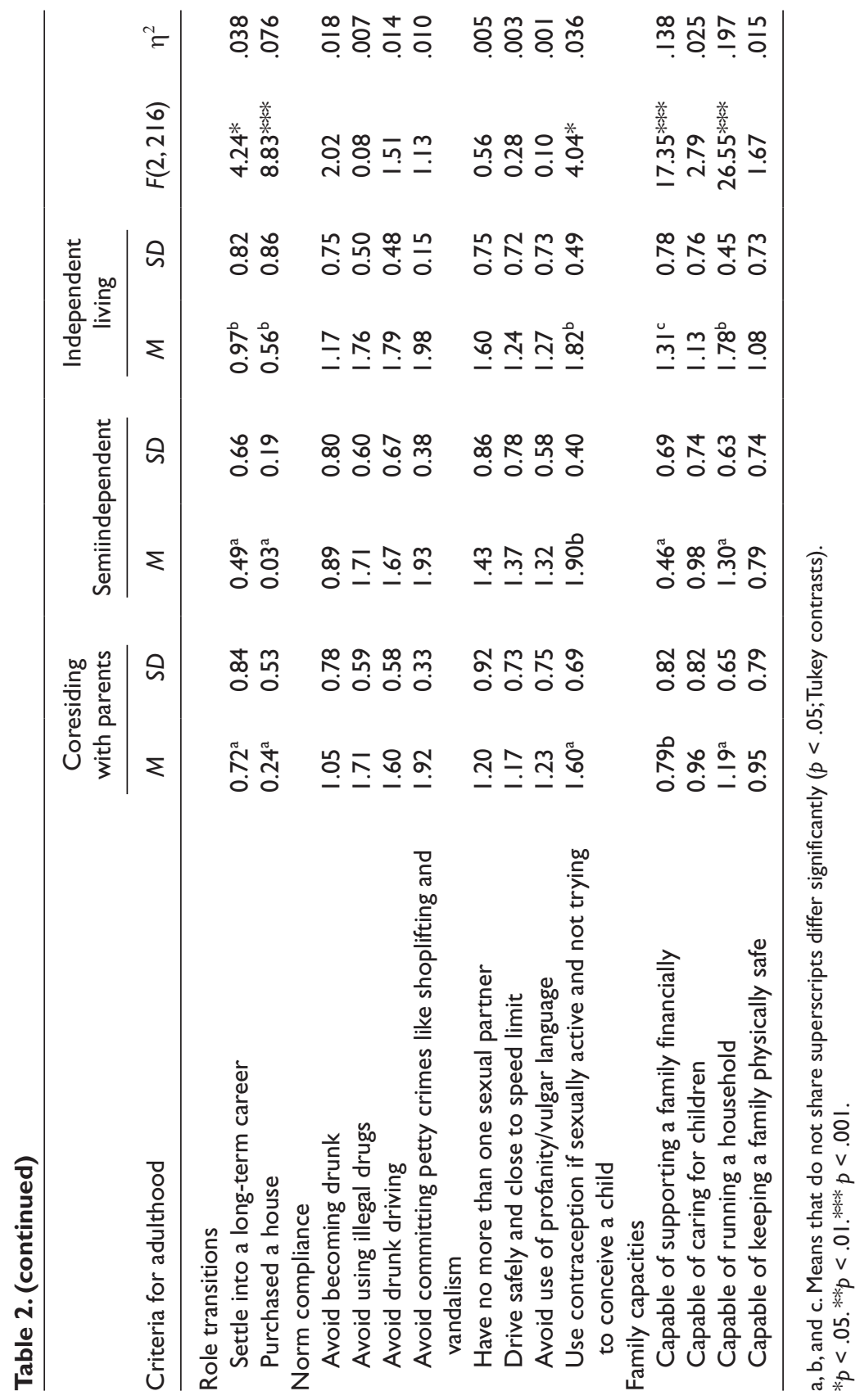


repeated measures MANCOVAs were performed, including both the main effects of time (the within-subjects factor) and $\Delta$ living situation (betweensubjects factor) as well as their interaction. Results of the various repeatedmeasures analyses, performed separately for each the theoretically distinguished groups of items, revealed significant multivariate effects of time on items reflecting interdependence, $F(4,211)=7.52, p<.001, \eta^{2}=.13$; role transitions, $F(6,209)=3.47, p<.01, \eta^{2}=.09$; and norm compliance, $F(8,207)=$ $4.26, p<.001, \eta^{2}=.14$. Furthermore, a significant multivariate effect of $\Delta$ living situation emerged for all subscales, except for norm compliance: independence, $F(20,697)=2.10, p<.01, \eta^{2}=.05$; interdependence, $F(16,645)=1.71, p<.05, \eta^{2}=.03$; role transitions, $F(24,730)=2.87, p<$ $.001, \eta^{2}=.08$; and family capacities, $F(16,645)=4.64, p<.001, \eta^{2}=.08$. Finally, none of the subscales showed significant multivariate Time $\times \Delta$ Living Situation interactions.

Subsequent univariate analyses for items tapping interdependence showed only a significant effect of time on being committed to a long-term love relationship, $F(1,214)=26.49, p<.001, \eta^{2}=.13$, indicating an overall increase in the engagement in stable partner relationships from Time $1(M=1.30)$ to Time $2(M=1.52)$. Next, regarding role transitions, results revealed that after 1 year more emerging adults had married (Time $1, \mathrm{M}=0.09$ vs. Time $2, M=$ 0.21 ), had at least one child (Time $1, M=0.11$ vs. Time $2, M=0.22$ ), and had settled into a long-term career (Time $1, M=0.72$ vs. Time $2, M=1.21$ ) $F(1,214)=4.59, p<.05, \eta^{2}=.02 ; F(1,214)=4.05, p<.05, \eta^{2}=.02 ;$ $F(1,214)=8.22, p<.01, \eta^{2}=.04$, respectively. Finally, time had a significant effect on two of the norm-compliance items: avoid drunk driving, $F(1,214)=$ $6.64, p<.05, \eta^{2}=.03$, and having no more than one sexual partner, $F(1,214)=$ $21.29, p<.001, \eta^{2}=.09$. Surprisingly, the overall mean score on the achievement of avoiding drunk driving was lower at Time $2(M=1.61)$ compared with Time $1(M=1.68)$.

Univariate effects of $\Delta$ living situation on the various criteria of adulthood are presented in Table 3. In case of significant effects, post hoc comparisons were requested in SPSS to indicate which of the types of $\Delta$ living situation differ significantly from one another. For the criteria representing independence, results of these pairwise comparisons showed that the stable independent succeeded significantly better in establishing a relationship with their parents as equal adults than those in the stable with parents group. Furthermore, the stable independent group scored higher on the achievement of financial independence than did participants in all other types of $\Delta$ living situation. Regarding the interdependence criteria, our findings indicate that the emerging adults in the stable with parents group were less committed to 


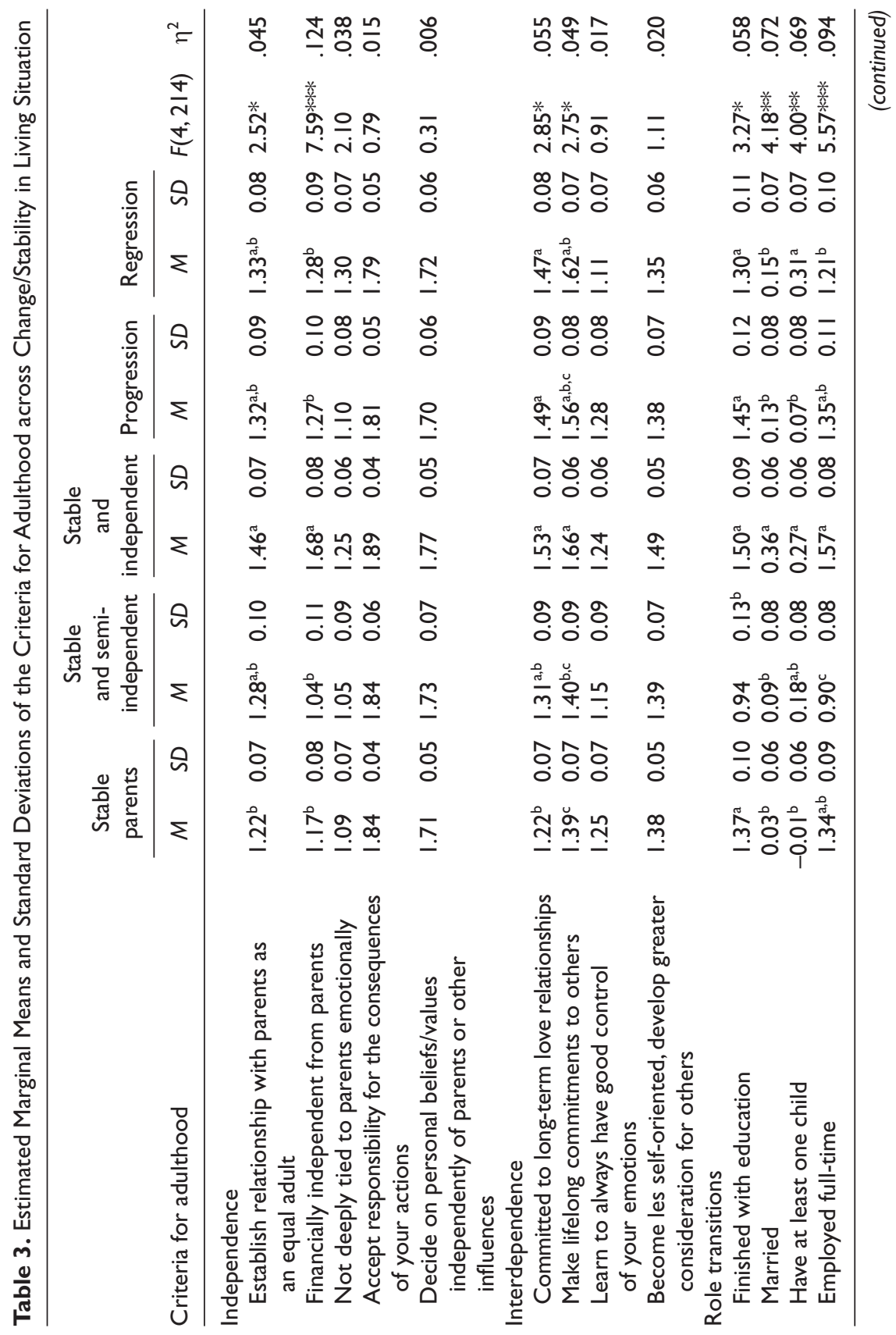




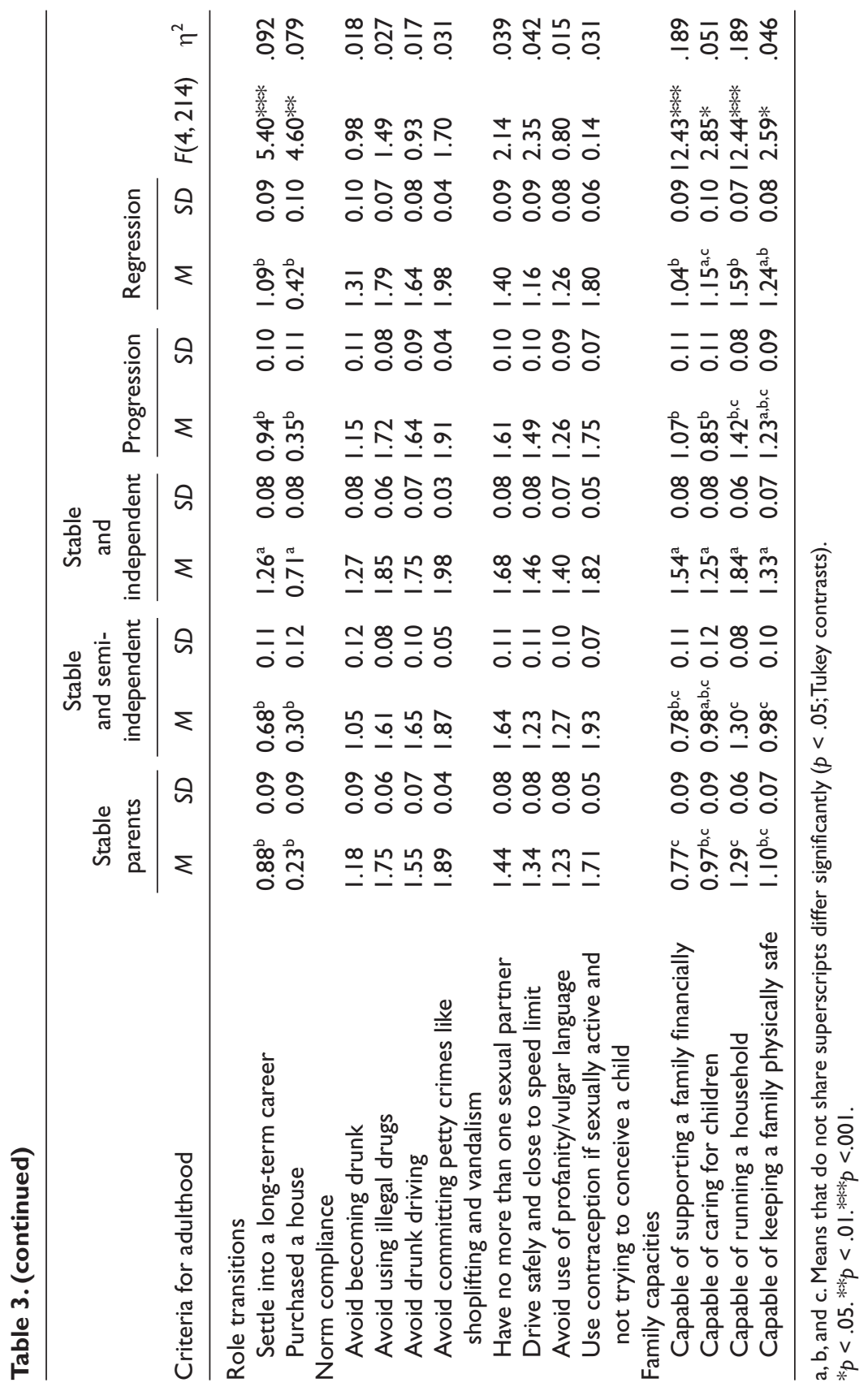


a long-term love relationship compared with the stable independent, progression, and regression group. In fact, the stable with parents group had in general made fewer lifelong commitments to others than the stable independent and regression group.

For all role transitions, the overall means differed depending on $\Delta$ living situation. First, the stable semiindependent group scored significantly lower concerning finishing off education than all others. Next, the overall mean for being married was significantly higher for the stable independent than for participants in the other categories. Furthermore, the stable independent and the regression group had on average more often children than did those in the stable with parents or progression group. Regarding employment, the stable independent group reported having a full-time job significantly more often than did those in the regression group, who in turn were more often employed full-time than were the stable semiindependent. Emerging adults in the stable with parents and progression group did not differ significantly from the stable independent and regression group with respect to the achievement of fulltime employment. However, when speaking about settling into a long-term career, the stable independent group outscored all the other groups. The same is true for purchasing a house.

Finally, effects of $\Delta$ living situation were found for all the criteria summarized as family capacities. The stable independent group had the highest scores on all four criteria reflecting achievement of family capacities. First, they reported to be capable of supporting a family financially more often than did emerging adults in the progression and regression group, who in turn scored higher compared to the stable with parents group. Next, the stable independent were more capable of caring for children than did those in the stable with parents and the progression group. Nevertheless, overall mean scores of respondents in the regression group on this criterion did not differ significantly from the stable independent, as well as the scores of the stable semiindependent that did not differ from any of the other groups. Top scores concerning being capable of running a household were again achieved by the stable independent, followed by the regression group, which in turn scored higher than the stable semiindependent and the group of emerging adults living stable with parents. Participants who progressed toward a more independent household scored significantly lower than the stable independent on this criterion, but their overall mean score did not differ significantly neither from the regression group nor from the stable with parents and stable semiindependent living emerging adults. Finally, the stable independent reported being more capable of keeping a family physically safe than did emerging adults in the stable with parents group, who in turn valued their capability higher than 
the stable semiindependent. The overall mean score of the regression group did not differ significantly from the stable independent and the stable with parents group, but this score was still significantly higher than that of the stable semiindependent. The progression group did not differ significantly from any other category on this criterion.

Although none of the subscales showed a significant multivariate Time $\times$ $\Delta$ Living Situation interaction, four significant univariate interactions were detected. Because tests of these interaction effects are rather conservative, we nevertheless decided to interpret them. Moreover, these effects merit our interest because they reflect different patterns of change over time in the achievement of criteria for adulthood for the various categories representing change/stability in living situation. Univariate Time $\times \Delta$ Living Situation interaction effects emerged for achieving financial independence from parents, $F(4,214)=3.65, p<.01, \eta^{2}=.06$; being committed to a long-term love relationship $F(4,214)=3.39, p<.05, \eta^{2}=.06$; avoiding drunk driving, $F(4$, $214)=2.98, p<.05, \eta^{2}=.05$; and being capable of running a household, $F(4$, $214)=3.29, p<.05, \eta^{2}=.06$. Figure 1 shows the change in achievement of these four criteria for adulthood from Time 1 to Time 2 for the five different categories of $\Delta$ living situation.

Results show that the progression group increased most in gaining financial independence from parents, making commitments to a long-term love relationship, and being capable of running a household. The stable independent living nevertheless kept scoring highest on these criteria at Time 2, except for commitment to a long-term love relationship. Those who move back toward a less independent living situation make the least progress or even regress somewhat. However, their scores at Time 2 continued to be higher or close to the scores of those in stable with parents and the stable semiindependent groups. Avoiding drunk driving, on the other hand, became more difficult for most emerging adults, except for those in a stable semiindependent residential status. The regression group relapsed most with respect to the avoidance of drunk driving; consequently, at Time 2 their scores were equal to those of the stable with parents group. The progression group decreased least on this criterion. Their scores at Time 2 were between the low scores of those in the stable with parents and regression group and the high scores of those in stable semiindependent and independent groups.

\section{Achievement of Adult Criteria and Subjective Well-Being}

In the last set of analyses, we investigated whether change in the achievement of criteria for adulthood over time results in improving subjective well-being 


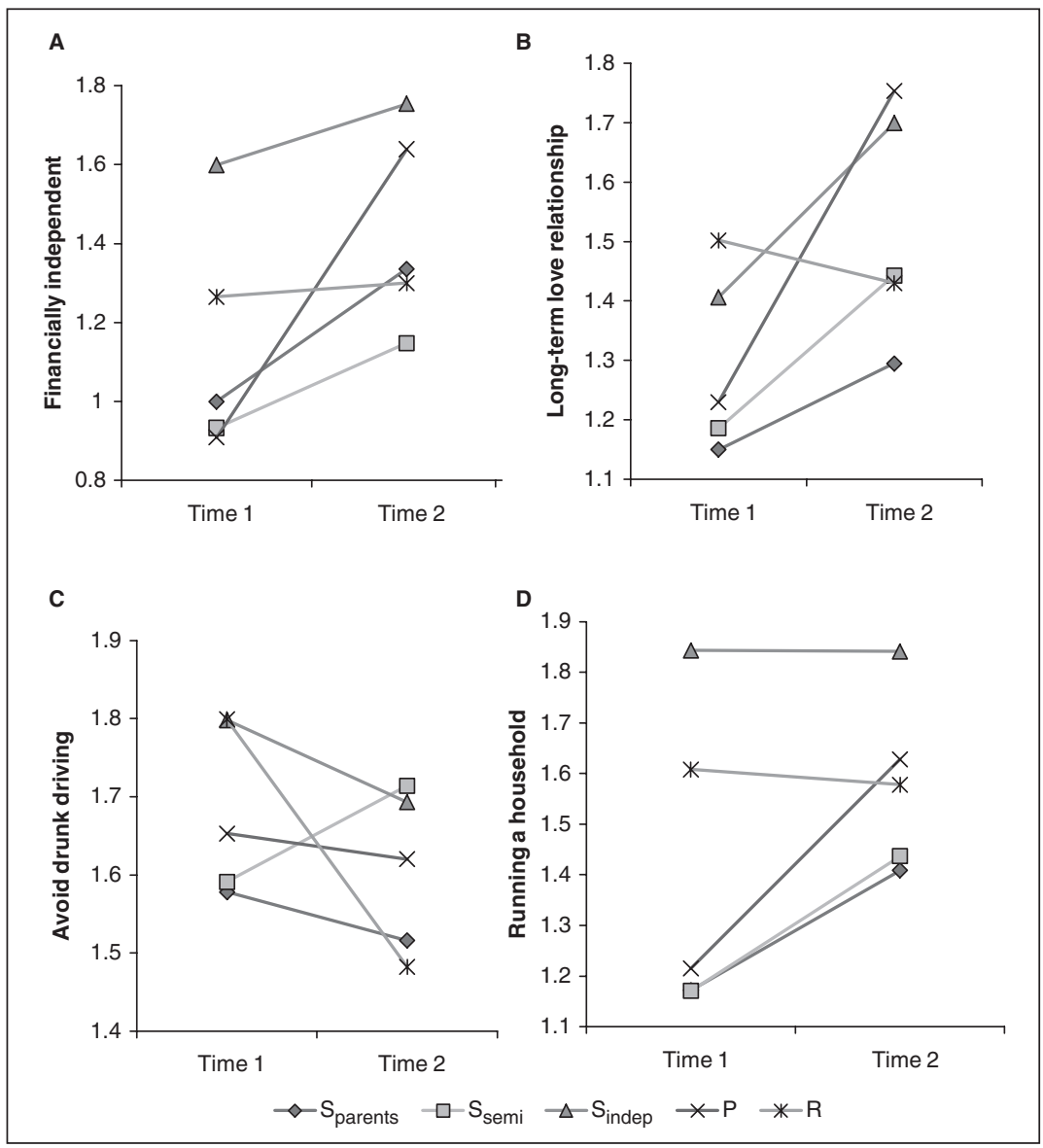

Figure I. Estimated marginal means of the following criteria for adulthood: Financially independent from parents (A), committed to a long-term love relationship (B), avoid drunk driving (C), and capable of running a household (D) across time for the five different categories reflecting change/stability in living situation over time (stable with parents, $\mathrm{S}_{\text {parents }}$; stable semiindependent, $\mathrm{S}_{\text {semi; }}$; stable independent, $\mathrm{S}_{\text {indep }}$; progression, $\mathrm{P}$; and regression, $\mathrm{R}$ ).

and whether there are particular criteria responsible for this. Initially, correlational analyses were conducted to explore how achievement of the various criteria of adulthood both at Time 1 and Time 2 relates to subjective well-being measured both at Time 1 and Time 2. Results revealed that the achievement of 
most criteria for adulthood was positively related with well-being. For reasons of conciseness, not all significant correlations are reported. The highest significant correlations with subjective well-being were found for the achievement of criteria reflecting independence (i.e., establishing a relationship with parents as an equal adult, being financially independent from parents, and not deeply tied to parents emotionally), interdependence (i.e., committed to a long-term love relationship, and learn to always have good control of emotions), and family capacities (i.e., capable of supporting a family financially). To further investigate the relationship between change in achieving adulthood and change in well-being, we performed hierarchical linear regression analyses with subjective well-being measured at Time 2 as the dependent variable. To control for subjective well-being experienced at Time 1 and for achievement of the criteria for adulthood at Time 1, these variables were entered in Step 1. Achievement of the criteria of adulthood reported at Time 2 were entered in Step 2 as predictors. As such, we predicted relative changes in subjective well-being as a consequence of changes in achievement of criteria for adulthood. Again, separate analyses were run for the criteria organized by different subscales.

In each of the models tested, subjective well-being reported at Time 1 was the most important predictor of well-being at Time $2(\beta=.68$ on average, $p<.001)$. Achievement of criteria of adulthood at Time 1 did not contribute significantly to changes in subjective well-being at Time 2, expect for one of the norm-compliance criteria, that is, avoid using illegal drugs $(\beta=.14, p<.05)$. Adding achievement of the criteria of adulthood at Time 2 as new predictors to the model significantly improved the predictive power of the model, and this for all models tested $\left(\Delta R^{2}=.03\right.$ to $\left..05, p<.05\right)$. For the criteria reflecting independence, results showed that achieving financial independence from parents $(\beta=.15, p<.01)$ positively predicted changes in well-being. With respect to interdependence, making lifelong commitments to others $(\beta=.14, p<.01)$ and having good control over emotions $(\beta=.13$, $p<.05$ ) predicted positive changes in well-being. Furthermore, the only role transition that contributed significantly to subjective well-being seemed to be settling into a long-term career $(\beta=.16, p<.01)$. As for norm compliance, avoiding the use of illegal drugs at Time $2(\beta=.20, p<.01)$ again positively predicted subjective well-being. Surprisingly, achievement of sexual monogamy (i.e., having no more than one sexual partner; $\beta=-.18, p<.01$ ) was the one criterion of adulthood that negatively predicted well-being. Finally, of the family capacities subscale, being capable of supporting a family financially $(\beta=.21, p<.001)$ positively predicted change in emerging adults' level of well-being. 


\section{Discussion}

The present study focused on emerging adults' developmental pathway toward an adult status. We examined whether delayed home-leaving affects the achievement of adulthood. Furthermore, the impact of achieving adult criteria on the amount of well-being during emerging adulthood was studied.

\section{Emerging Adults' Transition to Adulthood}

In accordance with Arnett (2001), results clearly show that adulthood is multidimensional, with emerging adults feeling that they have achieved adulthood by some criteria but not by others. Whereas the majority of emerging adults have achieved physical maturity and compliance to social norms, other dimensions of adulthood stay behind. For instance, although emerging adults gain more independence from parents, they are still highly preoccupied with redefining the hierarchical parent-child relationship into a relationship between equal adults. Furthermore, most emerging adults are involved in work-related role transitions, whereas the achievement of family-oriented role transitions (marriage and childbearing) stay behind. According to Arnett (2004), emerging adults are highly self-focused; therefore, it is not surprising that they are mostly struggling with criteria that reflect commitment to others and family capacities. Nevertheless, over time emerging adults particularly evolve in this area, as they establish more stable partner relationships. As emerging adults grow older they also increasingly settle themselves into a long-term career and comply more with social norms. However, emerging adults in our sample became less successful in the avoidance of drunk driving. It is feasible that as young people gain driving experience they become more confident about their driving skills even when they had a few drinks. Maybe don't-drink-and-drive campaigns should also address to older target groups, instead of focusing mainly on young people who recently obtained their drivers' license.

\section{Adulthood and Emerging Adults' Living Situations}

Findings revealed that the achievement of some adult criteria is related to emerging adults' type of living situation. Similar to previous studies, it was found that emerging adults in Belgium can be roughly categorized as coresiding with parents, living semiindependent, and living fully independent (de Jong Gierveld et al., 2001; Goldscheider \& DaVanzo, 1986; Mayseless, 2004). Contrary to our expectations, achievement of various dimensions of 
adulthood appeared to be connected with emerging adults' residential status and not solely the achievement of individualistic qualities. In line with the ideas of SIT (Blos, 1967, 1979), results consistently showed that independently living emerging adults succeed best in achieving the adult status. Thus, we can confirm that independently living emerging adults are not only successful in transforming the hierarchical parent-child relationship toward a relationship of mutual support (Aquilino, 1997; Dubas \& Petersen, 1996; Flanagan et al., 1993) but are also more financially independent, make lifelong commitments to others more often, and have achieved role transitions and family capacities more frequently than their peers in less independent living situations. Emerging adults who coreside with their parents are, by contrast, poorest at achieving an adult status with the exception of finishing off education and full-time employment. Emerging adults who live semiindependently have achieved these criteria that reflect the transition from school to work life the least because the group comprises the highest number of college students.

Apart from examining contemporaneous associations between living situation and achievement of adult criteria, we also examined associations between changes in both constructs. Young people who moved toward a more independent type of living situation made most progress concerning their financial status, relationship status, and perceived skills to run a household. Emerging adults who continue to live independently, will have achieved most of these criteria already and thus they do not make that much progress anymore over time. The emerging adults who permanently live with their parents or semiindependent made progress too, over time; however, they still scored lowest on the achievement of these adult criteria. Surprisingly, moving back to a less independent living situation did not completely undo the criteria that are achieved during the period of independent living. It seems that these emerging adults preserve what they have attained before; therefore, they are different from their peers who have never left the parental home, keeping intact their achievement of adult criteria. In sum, it can be concluded that leaving to a more independent residential status is important for emerging adults' pathway to adulthood, even if one would return to the parental home afterwards, as it is associated with growth in particular criteria, for adulthood.

As mentioned before, avoiding drunk driving is the one criterion that acts like an outsider, as no growth but decline is recorded. For this criterion, it does not hold true that once it is achieved, it is preserved. For young people moving back to the home of parents, this decline is sharpest and brings them close to emerging adults continuously residing with parents. It is not entirely clear 
why young people who live with their parents, either after a period of independent living or otherwise, engage more in this type of reckless behavior. Surprisingly, the semiindependent participants are the only ones who improve in avoiding drunk driving. Together with their stable independent living peers, they seem to be most responsible. Emerging adults who progressed to a more independent residential status scored somewhat in between and deteriorated least on this criterion. Hence, although most emerging adults seem to become less careful about drunk driving, again those living with their parents, but also those moving back into the parental household seem to take on the least adult responsibilities.

\section{Adulthood and Subjective Well-Being}

In line with earlier research (Galambos et al., 2006; Galambos \& Krahn, 2008; Schulenberg et al., 2004), it was found that the achievement of criteria for adulthood is related to more subjective well-being. Hence, even though Western cultures are highly focused on youthfulness (Fry, 1996), achieving adult maturity is associated with experiences of higher well-being. Except for avoiding the use of illegal drugs, no criterion achieved at an earlier time was predictive of change in the amount of well-being. Instead, change made in the achievement of adult criteria in 1 year did predict improvement in emerging adults' well-being. Particularly growth in criteria reflecting independence and interdependence leads to more well-being. That is, when emerging adults become more financially independent from their parents and when they grow in making lifelong commitments to others and having good control over their emotions, they experience improvement in wellbeing. But also the more emerging adults succeed in settling themselves into a long-term career, avoid the use of illegal drugs, and are capable of supporting a family financially, the more well-being they experience. For only one criterion, growth to a more adult status predicted declining well-being: having no more than one sexual partner. Because emerging adults are in the process of becoming less self-oriented, in order to commit themselves to enduring relationships with others (Arnett, 2004), this specific restriction is possibly quite a heavy burden for them.

\section{Strengths and Limitations}

This study clearly confirmed that adulthood is a multifaceted construct. Therefore, if we want to fully capture the multidimensional character of the adults status, future research should no longer ask respondents whether they 
have reached adulthood in general but tap into each of the dimensions separately. Arnett's scale containing various adult criteria can be used for this purpose. However, a thorough study on the improvement of the internal factor structure of this scale is needed first, before we will be able to work with scale scores for the separate dimensions of adulthood. Moreover, when studying emerging adults' transition to adulthood, their living situation should always be taken into account, as findings suggest that one's residential status is related to the pace of the process toward adulthood.

Although this study revealed some interesting findings, the nonrepresentativeness of our sample queries the generalization of the results. Future cross-cultural research with representative samples is warranted before we can feel confident about generalizing our conclusions to all emerging adults. It would for instance be interesting to investigate whether late home leaving has the same implications in Southern European countries, where it is more common to live with your parents during emerging adulthood, compared with Northern European countries like Belgium. Nevertheless, the results of this study are of note because they reveal some new insights into the developmental process to adulthood. This is one of the first studies that considers emerging adults' achievement of an adult status for each of the dimensions of adulthood separately. Furthermore, this study pointed out the important role of emerging adults' living situation in the transition to adulthood. Delayed home leaving can be an unfavorable living situation for emerging adults, as results suggest that coresiding with parents in emerging adulthood is associated with a delay in the achievement of some important criteria for adulthood. These relationships not only became apparent in the cross-sectional part of our research but were also confirmed over time. However, future research that takes into account other relevant variables, such as quality of the parent-child relationship and motives for the living situation, is needed to find out whether delayed home leaving is truly detrimental under all circumstances. Possibly, for emerging adults who live in an autonomy-supportive family, have good relationships with their parents, and who fully support the choice for this type of living situation, coresiding with parents has less negative effects.

Another strength of this study is that, even after controlling for background variables with substantial effects on the achievement of adult criteria, a strong connection between living situation and achievement of adulthood and well-being was found. In line with these findings, future research should explore the robust effects of these control variables further. Especially partnership status (i.e., having a partner or not) is an underexplored variable that seems to be quite crucial for emerging adults' development to adulthood. 
Qualitative research could be useful to further investigate the role partnership plays in becoming an adult.

\section{Conclusion}

Emerging adults are making the transition to an adult status. However, the course of this developmental process seems to be connected to the living situation during this phase of life. Independent living appears to be associated with a an accelerated attainment of certain criteria for adulthood, whereas continued coresidence with parents proved to stunt this process. Moreover, progress in the achievement of adult criteria is positively related to emerging adults' well-being. Therefore, developmental psychologists and clinicians would do well to pay attention to the potentially harmful implications delayed home leaving can have during this stage of life.

\section{Declaration of Conflicting Interests}

The author(s) declared no conflicts of interest with respect to the authorship and/or publication of this article.

\section{Funding}

The author(s) received no financial support for the research and/or authorship of this article.

\section{References}

Aquilino, W. S. (1997). From adolescent to young adult: A prospective study of parent-child relations during the transition to adulthood. Journal of Marriage and Family, 59, 670-686.

Arnett, J. J. (1998). Learning to stand alone: The contemporary American transition to adulthood in cultural and historical context. Human Development, 41, 295-315.

Arnett, J. J. (2000). Emerging adulthood: A theory of development from the late teens through the twenties. American Psychologist, 55, 469-480.

Arnett, J. J. (2001). Conceptions of the transition to adulthood: Perspectives from adolescence through midlife. Journal of Adult Development, 8, 133-143.

Arnett, J. J. (2003). Conceptions of the transition to adulthood among emerging adults in American ethnic groups. New Directions for Child and Adolescent, 100, 63-76.

Arnett, J. J. (2004). Emerging adulthood. The winding road from the late teens through the twenties. New York: Oxford University Press.

Arnett, J. J., \& Galambos, N. L. (Eds.). (2003). New directions for child and adolescent development: Exploring cultural conceptions of the transition to adulthood. San Francisco: Jossey-Bass. 
Badger, S., Nelson, L. J., \& Barry, C. N. (2006). Perceptions of the transition to adulthood among Chinese and American emerging adults. International Journal of Behavioral Development, 30, 84-93.

Barker, E. T., \& Galambos, N. L. (2005). Adolescents' implicit theories of maturity: Ages of adulthood, freedom, and fun. Journal of Adolescent Research, 20, 557-576. Blos, P. (1967). The second individuation process of adolescence. Psychoanalytic Study of the Child, 22, 162-186.

Blos, P. (1979). The adolescent passage. Madison, CT: International Universities Press.

Bouma, J., Ranchor, A. V., Sanderman, R., \& van Sonderen, E. (1995). Het meten van symptomen van depressie met de CES-D: Een handleiding [Measuring symptoms of depression with CES-D: A manual] (Internal report). Groningen, the Netherlands: University Groningen.

Buhl, H. M., \& Lanz, M. (2007). Emerging adulthood in Europe: Common traits and variability across five European countries. Journal of Adolescent Research, 22, 439-443.

Cherlin, A. J., Scabini, E., \& Rossi, G. (1997). Still in the nest: Delayed home leaving in Europe and the United States. Journal of Family Issues, 18, 572-575.

Clemens, A. W., \& Axelson, L. J. (1985). The not-so-empty-nest: The return of the fledgling adult. Family Relations, 34, 259-264.

de Jong Gierveld, J., Liefbroer, A. C., \& Dourleijn, E. (2001). Je bent jong en je wilt wat . . Patronen van uit huis gaan in 16 Europese landen en in de USA [Aspirations when being young: Patterns of home leaving in 16 European countries and the USA]. Bevolking en Gezin, 30, 77-100.

Diener, E., Emmons, R. A., Larsen, R. J., \& Griffin, S. (1985). The satisfaction with life scale. Journal of Personality Assessment, 49, 71-75.

Dubas, J. S., \& Petersen, A. C. (1996). Geographical distance from parents and adjustment during adolescence and young adulthood. New Directions for Child Development, 71, 3-19.

Elm, S. D., \& Schwartz, K. D. (2006, March 23-26). Are you in or are you out?: Living arrangements and identity development during emerging adulthood. Poster presented at the 2006 SRA Biennial Meeting, San Francisco.

Erikson, E. H. (1968). Identity: Youth and crisis. New York: Norton.

Flanagan, C., Schulenberg, J., \& Fuligni, A. (1993). Residential setting and parentadolescent relationships during the college years. Journal of Youth and Adolescence, 22, 171-189.

Fry, C. L. (1996). Age, aging, and culture. In R. H. Binstock \& L. K. George (Eds.), Handbook of aging and the social sciences (pp. 117-136). San Diego, CA: Academic Press. 
Fussell, E., Gauthier, A. H., \& Evans, A. (2007). Heterogeneity in the transition to adulthood: The cases of Australia, Canada and the United States. European Journal of Population, 23, 389-414.

Galambos, N. L., \& Krahn, H. J. (2008). Depression and anger trajectories during the transition to adulthood. Journal of Marriage and Family, 70, 15-27.

Galambos, N. L., Barker, E. T., \& Krahn, H. J. (2006). Depression, self-esteem and anger in emerging adulthood: Seven-year trajectories. Developmental Psychology, 42, 350-365.

Galland, O. (1997). Leaving home and family relations in France. Journal of Family Issues, 18, 645-670.

Gitelson, I. B., \& McDermott, D. (2006). Parents and their young adult children: Transitions to adulthood. Child Welfare, 5, 853-866.

Goldscheider, F., \& Davanzo, J. (1986). Semiautonomy and leaving home during early adulthood. Social Forces, 65, 187-201.

Goldscheider, F. (1997). Recent changes in U.S. young adult living arrangements in comparative perspective. Journal of Family Issues, 18, 708-724.

Goldscheider, F., \& Goldscheider, C. (1999). The changing transition to adulthood. Leaving and returning home. Thousand Oaks, CA: Sage.

Gottlieb, B. H., Still, E., \& Newby-Clark, I. R. (2007). Types and precipitants of growth and decline in emerging adulthood. Journal of Adolescent Research, 22, 132-155.

Grotevant, H. D., \& Cooper, C. R. (1986). Individuation in family relationshipsA perspective on individual differences in the development of identity and roletaking skill in adolescence. Human Development, 29, 82-100.

Hambleton, R. K. (1994). Guidelines for adapting educational and psychological tests: A progress report. European Journal of Psychological Assessment, 10, 229-244.

Hanewald, G. J. F. P. (1987). CES-D, de Nederlandse versie: Een onderzoek naar de betrouwbaarheid en de validiteit [CES-D, The Dutch version: A study of the reliability and validity]. Amsterdam: Universiteit van Amsterdam.

Iacovou, M. (2001). Leaving home in the European Union (ISER Working Paper 2001-18). Colchester, UK: Institute for Social and Economic Research.

Kins, E., Beyers, W., Soenens, B., \& Vansteenkiste, M. (2009). Patterns of home leaving and subjective well-being: The role of motivational processes and parental autonomy support. Developmental Psychology, 45, 1416-1429.

Little, R. J. A. (1988). Missing data in large surveys. Journal of Business and Economic Statistics, 6, 287-301.

Lodewijckx, E. (2008). Veranderende leefvormen in het Vlaamse Gewest 1990-2007 (en 2021). Een analyse van gegevens uit het Rijksregister. Studiedienst van de Vlaamse Regering, Vlaamse Overheid [Changing living conditions in the Flemish 
region, 1990-2007 (and 2021). An analyses from data of the state register. Internal Affairs, Flemish Government]. Brussels: Belgium.

Luyckx, K., Schwartz, S. J., Goossens, L., \& Pollock, S. (2008). Employment, sense of coherence, and identity formation. Contextual and psychological processes on the pathway to sense of adulthood. Journal of Adolescent Research, 23, 566-591.

Mayseless, O. (2004). Home leaving to military service: Attachment concerns, transfer of attachment functions from parents to peers and adjustment. Journal of Adolescent Research, 19, 533-558.

Mayseless, O., \& Scharf, M. (2003). What does it mean to be an adult? The Israeli experience. New Directions for Child and Adolescent Development, 100, 5-20.

National Institute for Statistics. (2008). Publications on population: Marriages and divorces - child birth. Retrieved August 11, 2008, from http://statbel.fgov.be/

Niemiec, C. P., Lynch, M. F., Vansteenkiste, M., Bernstein, J., Deci, E. L., \& Ryan, R. M. (2006). The antecedents and consequences of autonomous self-regulation for college: A self-determination theory perspective on socialization. Journal of Adolescence, 29, 761-775.

Nelson, L. J., \& Barry, C. M. (2005). Distinguishing features of emerging adulthood: The role of self-classification as an adult. Journal of Adolescent Research, 20, 242-262.

Nylund, K. L., Asparouhov, T., \& Muthen, B. (2007). Deciding on the number of classes in latent class analysis and growth mixture modeling. A Monte Carlo simulation study. Structural Equation Modeling, 14, 535-569.

Pavot, W., Diener, E., Colvin, C. R., \& Sandvik, E. (1991). Further validation of the Satisfaction with Life Scale: Evidence for the cross-method convergence of wellbeing measures. Journal of Personality Assessment, 57, 149-161.

Radloff, L. S. (1977). The CES-D scale: A self-report depression scale for research in the general population. Applied Psychological Measurement, 1, 385-401.

Ryan, R. M., \& Frederick, C. (1997). On energy, personality and health: Subjective vitality as a dynamic reflection of well-being. Journal of Personality, 65, 529-565.

Schafer, J. L. (1997). Analysis of incomplete multivariate data (Monographs on Statistics and Applied Probability, 72). London: Chapman \& Hall.

Schulenberg, J. E., Bryant, A. L., \& O’Malley, P. M. (2004). Taking hold of some kind of life: How developmental tasks relate to trajectories of well-being during the transition to adulthood. Development and Psychopathology, 16, 1119-1140.

Settersten, R. A., Furstenberg, F. F., \& Rumbaut, R. G. (2005). On the frontier of adulthood. Theory, research and public policy. Chicago: University of Chicago Press.

Sirsch, U., Dreher, E., Mayr, E., \& Willinger, U. (2009). What does it take to be an adult in Austria? Views of adulthood in Australian adolescents, emerging adults and adults. Journal of Adolescent Research, 24, 275-292. 
Tanner. J. L. (2006). Recentering during emerging adulthood: A critical turning point in life span human development. In J. J. Arnett \& J. L. Tanner (Eds.), Emerging adults in America. Coming of age in the 21st century (pp. 21-55). Washington, DC: American Psychological Association.

Vermunt, J. K. (1997). LEM: A general program for the analysis of categorical data. Tilburg, Netherlands: Tilburg University.

Vettenburg, N., Elchardus, M., \& Walgrave, L. (2007). Jongeren in cijfers en letters. Bevindingen uit de JOP-monitor 1 [Young people in Flanders: Facts and Figures. Findings of JOP-Monitor 1]. Leuven, Belgium: Lannoo Campus.

White, N. R. (2002). 'Not under my roof!” Young people's experience of home. Youth \& Society, 34, 214-231.

\section{Bios}

Evie Kins is pursuing a $\mathrm{PhD}$ in psychology and educational sciences in the Department of Developmental, Personality, and Social Psychology, Ghent University, Belgium.

Wim Beyers is a lecturer in developmental psychology at Ghent University, Department of Developmental, Personality, and Social Psychology He received his PhD in psychology from the Catholic University of Leuven, Belgium, in 2001. His research interests include adolescents' social and emotional development. 